\title{
Organisational design elements and competencies for optimising the expertise of knowledge workers in a shared services centre
}

\begin{abstract}
Authors:
Mark Ramsey ${ }^{1}$

Nicolene Barkhuizen ${ }^{2}$

Affiliations:

${ }^{1}$ Department of Industrial

Psychology and People

Management, University of

Johannesburg, South Africa

${ }^{2}$ Department of Human

Resource Management,

University of Pretoria,

South Africa

Correspondence to:

Nicolene Barkhuizen

Email:

nicolene.barkhuizen@up.ac. za

Postal address:

Economic and Management

Sciences Building, University of Pretoria, Lynnwood Road,

Hillcrest, Pretoria 0002

Dates:

Received: 01 June 2010

Accepted: 16 Mar. 2011

Published: 23 Aug. 2011

How to cite this article: Ramsey, M, \& Barkhuizen, N. (2011). Organisational design elements and competencies for optimising the expertise of knowledge workers in a shared services centre. SA Journal of Human Resource Management/SA Tydskrif vir Menslikehulpbronbestuur, 9(1), Art. \#307, 15 pages. doi:10.4102/sajhrm.v9i1.307
\end{abstract}

C 2011. The Authors. Licensee: OpenJournals Publishing. This work is licensed under the Creative Commons Attribution License.
Orientation: Organisations are still structured according to the Industrial Age control model that restricts optimising the expertise of knowledge workers.

Research purpose: The general aim of the research was to explore the organisation design elements and competencies that contribute to optimising the expertise of knowledge workers in a shared services centre.

Motivation for the study: Current organisational design methodologies do not emphasise optimising the expertise of knowledge workers. This research addresses the challenge of how an organisation design can improve the creation and availability of the expertise of knowledge workers.

Research design/approach method: The researcher followed a qualitative case study research design and collected data in six focus group sessions $(N=25)$.

Main findings: The findings showed that the shared services centre (SSC) is not designed to enable its structure, culture and codifying system to optimise the expertise of knowledge workers. In addition, the SSC does not share the knowledge generated with other knowledge workers. Furthermore, it does not use the output of the knowledge workers to improve business processes.

Practical/managerial implications: The expertise of knowledge workers is the basis of competitive advantage. Therefore, managers should create an organisational design that is conducive to optimising knowledge work expertise.

Contribution/value add: This research highlights the important organisational design elements and supportive organisational structures for optimising the expertise of knowledge workers. The research also proposes a framework for optimising the expertise of knowledge workers and helping an organisation to achieve sustainable competitive advantage.

\section{Introduction}

The success of an organisation depends on the mental capability of a comparatively small number of highly proficient knowledge workers who clarify the business processes others must act on (Zemke, 2004). Many organisations use the expertise of knowledge workers to create competitive advantage. However, they do not incorporate this expertise into their business processes and routine operations (Barber \& Strack, 2005; Hornstein \& De Guerre, 2006; Seidler-de Alwis \& Hartmann, 2008). Therefore, when knowledge workers leave an organisation, the organisation loses the knowledge they generate and cannot sustain its competitive advantage (Bryan \& Joyce, 2005).

One of the foremost objectives of an organisation should be to optimise the expertise of its knowledge workers to produce new products, services or ways of working in order to sustain competitive advantage (Gold, Malhotra, \& Segards, 2001; Grandori \& Soda, 2006; Massey \& Montoya-Weiss, 2006).

However, it appears that current organisational designs do not emphasise optimising the expertise of knowledge workers. According to Covey (2004), managers still apply the Industrial Age control model to knowledge workers. Despite all the achievements in technology and improvements to products, knowledge workers are not thriving in the organisations where they 
work because the organisations are not clear about where knowledge workers fit and how to value their contributions (Kenney \& Gudergan, 2006; Wang-Cowham, 2008). Process technology describes the technical aspects of production and the kinds of specialised knowledge organisations need for their business processes. However, dividing responsibilities between knowledge workers and departments as well as specifying the interfaces between them falls within the sphere of organisational design (Spira, 2005).

Therefore, the challenge for organisations in the new economy is to optimise, create, transfer, assemble, protect and exploit knowledge assets (Boder, 2006; Sharkey, 2006; Stenmark, 2001). Knowledge assets underpin organisational competencies that, in turn, underpin an organisation's products and services (Meilich, 2005). The more specific the knowledge an organisation uses, the greater is its potential as a basis for competitive advantage (Johanson, Martensson \& Skoog, 2001; Marouf, 2007).

However, knowledge workers actually hold the knowledge (Laise, Migliarese \& Verteramo, 2005). Therefore, an organisation's focus should be to optimise their expertise (Meilich, 2005).

Knowledge workers are highly qualified and well-educated professionals whose work consists largely of using their expertise to convert information into knowledge (Hammer, Leonard \& Davenport, 2004). Creating and exchanging knowledge and intangibles by interacting with their professional peers is central to what they do.

Knowledge workers make an organisation competitive. However, they find that the organisational design increasingly obstructs their work (Drucker, 1999; Seidlerde Alwis \& Hartmann, 2008). They spend endless hours searching for the knowledge they need and coordinating their work with others in the organisation (Bryan \& Joyce, 2005). An effective design option will allow an organisation to assemble and fine-tune its design in order to create and sustain its competitive advantage (Botha, 2000; 2007; Jarvenpaa \& Staples, 2001; Russo \& Harrison, 2005).

Against this background, the main purpose of the research is to:

- explore the organisational design elements that help an organisation to optimise the expertise of its knowledge workers

- determine which supportive organisational competencies an organisation needs to optimise the expertise of its knowledge workers.

The motivation for conducting this research is to address the challenge of how an organisation's design can improve the creation and availability of knowledge for sustainable competitive advantage.

The process of converting tacit knowledge into explicit knowledge has direct implications on how the structure of an organisation is designed. It also defines management roles as well as responsibilities.

To be sustainable, an organisational design must allow an organisation to recognise, create, transform and distribute knowledge. Therefore, the primary role of an organisation should be to optimise the expertise of knowledge workers, the focus of this research.

The next section of the article discusses the available literature on organisational design elements and supportive organisational competencies as they relate to optimising the expertise of knowledge workers. The design components and supportive organisational competencies are not intended to be exhaustive lists. Instead, they have been identified for their potential to optimise the expertise of knowledge workers, in accordance with Drejer and Sorensen (2002).

\section{Literature review}

\section{Organisational design elements to optimise the expertise of knowledge workers}

An organisation is an institution for applying knowledge (Johanson et al., 2001). Its primary role is to optimise the expertise of knowledge workers (Wang \& Ahmed, 2003).

As a knowledge-optimising institution, an organisation's role is not to acquire or create organisational knowledge. Those are the roles of knowledge workers (Johanson et al., 2001). Knowledge resides in knowledge workers (LaDuke, 2005) and an organisation must focus on visible organisational processes to support the structural arrangements that will optimise their expertise (Johanson et al., 2001). This requires an organisational design where an organisation uses its culture, structure and business processes to improve the expertise of knowledge workers $(\mathrm{Ng}$, 2004).

\section{Culture}

The culture of an organisation must contribute to a climate that facilitates the optimisation of the expertise of knowledge workers by encouraging creativity and innovation in the organisation. Organisational culture is the deeply rooted values and beliefs that all in an organisation share (Oliver \& Kandadi, 2006).

A strong organisational culture is crucial for optimising the expertise of knowledge workers because it is an integral part of the general functioning of an organisation. It also brings about the innovation that is a requirement for sustaining competitive advantage.

For the culture of an organisation to help to optimise the expertise of knowledge workers, it must have a strong set of core values and norms that encourage creating and sharing knowledge as well as the active participation of knowledge workers in the process (Lucas \& Ogilvie, 2006). Organisational culture embodies the expressive character of an organisation. Symbolism, feelings and the meanings behind language, behaviours, space and artefacts communicate it. 
The elements of an organisational culture affect the optimisation of the expertise of knowledge workers through socialisation processes in an organisation that enable knowledge workers to learn what behaviour is acceptable and how they should perform their activities (Martins \& Terblanche, 2003). In addition, knowledge workers act out the basic values, assumptions and beliefs in established forms of behaviours and activities that structures, policies, practices and procedures reflect.

Organisational culture affects the extent to which knowledge workers generate, share, transfer and reuse knowledge in an organisation. An organisation cannot use knowledge effectively if knowledge workers cannot locate or access it (Hicks, Dattero \& Galup, 2006). Organisations must encourage and support the creative activities of knowledge workers to optimise the expertise of knowledge workers. Organisations must not underestimate the challenge of building a supportive organisational culture to optimise the expertise of knowledge workers because culture exists in the deep structures of an organisation (Lai \& Lee, 2007).

\section{Structure}

In the new economy, knowledge assets are ingrained in the experience and expertise of the knowledge workers in an organisation. Therefore, an organisation must provide the right structures if it is to optimise their expertise (Smedlund, 2008).

An ideal organisational design must focus on establishing the structure and climate to facilitate optimising the expertise of knowledge workers by encouraging knowledge workers, who have tacit knowledge, to share it in the organisation (Koening, 1999). Tacit knowledge is the expertise that guides action (Rodriguez-Lluesma \& Bailey 2005) and is difficult to use because there is no real need to make it explicit at the individual level.

The problem of establishing which knowledge worker has the necessary knowledge grows with the size of an organisation (Stenmark, 2001). This type of knowledge is personal (Lebowitz, 2005) and resides only in the minds of knowledge workers (Holste \& Fields, 2005).

To create and sustain competitive advantage, the structure should facilitate the coordinated actions of its knowledge workers to transform an input into an organisational output (Boder, 2006). Coordination is a mechanism that regulates the interdependent objectives, tasks and responsibilities of different business units to achieve a business goal (Danese \& Romano, 2004; Jain, Nagar \& Srivastava, 2006).

The coordinating mechanism should try to redesign business processes by changing the organisational emphasis from functional to process orientation (Lee \& Dale, 1998) in order to discourage functional boundaries from becoming barriers to achieving competitive advantage (Zairi, 1997). An organisation uses its coordinating capabilities to promote the optimisation of the expertise of knowledge workers by using its increasing tacit knowledge. This results in greater scope, flexibility and increased efficiency in integrating knowledge types (Alsene, 2007).

Coordination facilitates the integration of tacit knowledge through horizontal and vertical relationships as well as learning in an organisation (Kenney \& Gudergan, 2006). The effectiveness of the coordinating structure determines the organisation's ability to optimise the expertise of its knowledge workers (Marouf, 2007).

To be sustainable in the new economy, an organisation must optimise the expertise of its knowledge workers by accelerating organisational learning to outpace its competitors in building new competitive advantages (Hamel \& Prahalad, 2005).

An organisation converts its experiences into promises for future actions. The expertise of knowledge workers is a building block for organisational learning. Consequently, an organisation successfully transfers the expertise of its knowledge workers to others who see it as useful (Brachos, Kostapoulos, Soderquist \& Practacos, 2007).

Tacit knowledge is critical for optimising the expertise of knowledge workers. An organisation needs it to create competitive advantage but can only transfer it through social interactions and detailed discussions amongst knowledge workers from similar backgrounds and with common experiences.

This social interaction leads to a high level of common knowledge, understanding, language and experience that support the efficient transfer of knowledge (Koners \& Goffin, 2007). Therefore, the organisational structure should be designed so that it maximises the interaction between knowledge workers to optimise the expertise of knowledge workers and improve learning (Pham \& Swierczek, 2006).

Optimising the expertise of knowledge workers means that an organisation must allow knowledge workers to improve their skills through processes that require reflection and dialogue to allow personal and organisational learning and innovation (Ballantine \& McCourt Larres, 2007).

For an organisation to optimise the expertise of its knowledge workers, it must create and maintain a dynamic work environment (Hasgall \& Shoham, 2008). In a work environment that is conducive to the generation, exchange and respect of knowledge, there would be an increase in morale, trust, collaboration and retention of knowledge workers (Teerajetgul \& Chareonngam, 2008).

Perceptions of fairness link inextricably to knowledge workers' views of the overall fairness of the work environment and affect the quality of the exchange (Ansari, Hung \& Aafaqi, 2007). A work environment is one manifestation of 
an organisational culture and a positive work environment that will improve the participation of knowledge workers in transferring knowledge. This will result in optimising their expertise (Rowold \& Hochholdinger, 2008). A positive work environment, according to Edvardsson, 2003, includes allowing knowledge workers:

- to influence and control their own work situations

- to develop security and meaning

- to develop social relations at, and through, the job

- to keep a social distance from the job

- good health

- to avoid negative stress

- to work in safe physical surroundings.

An organisation can improve its positive work environment further by including training, co-worker support, future prospects and organisational understanding (Duignan, 2007).

\section{Codification system}

An important requirement for optimising the expertise of knowledge workers in an organisation is to capture tacit knowledge and convert it into information that others can use later (Prieto \& Revilla, 2006).

The process organisations use to convert, transfer and distribute the acquired expertise of knowledge workers into a transferable form is important for optimising their expertise (Jantunen, 2005). The usual reason for codifying knowledge is to ensure greater standardisation and to disperse it throughout an organisation (Davies, Subrahmanian \& Westerberg, 2005). Therefore, codification is necessary whenever an organisation has to communicate knowledge.

An organisation can use many ways to transfer knowledge. They include face-to-face communication, telephone and email (Albina, Garavelli \& Gorgoglione, 2004). Codifying knowledge into information is the main method organisations use to transfer knowledge in an organisation. This view emphasises codifying knowledge as a way of transferring knowledge (Hall, 2006).

A codification strategy aims to collect knowledge, store it in databases and provide the available knowledge in an explicit and codified form. Reusing explicit knowledge and solutions can save time and money.

Designing databases and managing documents as well as workflow is part of this strategy. A codification strategy will succeed in an organisation whose business strategy requires it to reuse existing knowledge (Greiner, Böhmann \& Krcmar, 2007).

However, because an organisation can codify knowledge does not necessarily mean that it is available for use or that it automatically becomes available. Knowledge workers may be reluctant to share this knowledge because it may be sensitive in some situations or it might reflect poorly on them. In addition, knowledge workers may feel that they own this knowledge because it is a result of their own unique experiences. The codification process is uncertain and not automatic (Marouf, 2007). Knowledge that resists codification remains captive to the knowledge worker in which it resides and the context that it is bound to (Yakhlef, 2005).

\section{Supportive organisational competencies for optimising the expertise of knowledge workers}

For an organisation to sustain competitive advantage in the knowledge economy, it is vital for an organisation to develop organisational competencies to optimise the expertise of its knowledge workers.

Knowledge workers are highly educated experts with vast amounts of practical experience (Cooper, 2006) and give organisations the capacity to act (Botha, 2000). Therefore, knowledge workers provide focus and creativity by allowing all the organisation's other investments to achieve their objectives (Covey, 2004).

Knowledge workers cannot, and do not, seek life-long employment. They want life-long learning and career selfreliance. Their level of expertise makes achieving them possible (Bogdanowicz \& Bailey, 2002). The tacit knowledge that resides in their heads distinguishes knowledge workers from other employees. They are the agents of a knowledge organisation or its intellectual capital (Laise et al., 2005). To optimise the expertise of its knowledge workers, an organisation must focus on knowledge as well as managing, creating, transferring, sharing and communicating it.

\section{Knowledge}

Knowledge comprises a knower and is difficult to transfer and absorb. It requires context and is one facet of a larger system of knowing (Iverson \& McPhee, 2002). There are many definitions of knowledge. For purposes of this research, it is:

an organisation's knowledge creation capability, incorporating the extent to which the top management team and knowledge workers have access to one another and other stakeholders, are capable of combining information and knowledge into new knowledge and perceive value from the exchange and combination process.

(Smith, Collins \& Clark, 2005)

This definition of knowledge is preferred because it links very strongly to organisational performance (Peltonen \& Lamsa, 2004).

Therefore, the knowledge economy depends on optimising the expertise of knowledge workers and using knowledge resources within organisations to gain the most return from human capital (Levy, 2005; Janz \& Prasarnphanich, 2003).

The only way an organisation can maintain competitive advantage is to innovate by optimising the expertise of knowledge workers in order to create new knowledge (Pillania, 2005). Therefore, knowledge is explicit or tacit, codified or personal and organisational or individual (Alvesson, Karreman \& Swan, 2002). An organisation 
evolves by adapting the knowledge of its knowledge workers (Lee \& Cole, 2003) and much of this happens at a tacit level (Spender, 1996). What organisations need now is not increased information, but an increased ability to deal with that information (Thomas \& Hult, 2003; Levy, 2005).

\section{Managing knowledge}

Knowledge management has grown as organisations realise how much they have lost by not optimising the expertise of knowledge workers (Jackson, 2007). Business processes have become complex and dynamic. Knowledge work that requires high levels of skills and expertise is replacing manual labour (Janz \& Prasarnphanich, 2003).

An organisation should optimise the expertise of its knowledge workers by learning from their experiences to adapt to changes (Kirkwood \& Pangarkar, 2003). Managing knowledge effectively is critical to optimising the expertise of knowledge workers (Holste \& Fields, 2005; Poston \& Speier, 2005). Knowledge and skills that are valuable to an organisation tend to be embodied in knowledge workers and are difficult to replace (Keskin, 2005).

The speed of transactions in the new economy means that an organisation must have the ability to interpret and respond to information about changes in the environment almost instantaneously (Pillania, 2005). The amount of knowledge available on any subject is increasing to a level that is impossible to comprehend in its entirety (Owen, 1999).

Finding and choosing knowledge that is appropriate to the organisation or the individual knowledge worker seems an almost impossible task (Poston \& Speier, 2005). An organisation must use new technologies and innovate in time to anticipate changes in the marketplace (Thomas \& Hult, 2003). Knowing when, how and what to innovate is therefore key to optimising the expertise of knowledge workers (Owen, 1999). To deal with these challenges, an organisation needs to evaluate the way it acquires, creates, manages and uses knowledge (Poston \& Speier, 2005).

\section{Creating knowledge}

Successful and sustainable organisations continuously create new knowledge to optimise the expertise of knowledge workers (Smith et al., 2005), then distribute it widely and embody it in new products, services or ways of working (Robertson, Scarbrough \& Swan, 2003).

Knowledge develops through inductive or deductive logic (Akbar, 2003) whilst creating knowledge is an individual activity (McFadyen \& Cannella, 2004; Janz \& Prasarnphanich, 2003). However, new knowledge is created through a process of turning tacit knowledge into explicit knowledge, with less emphasis on work rules (Akbar, 2003; Muthusamy \& White, 2005).

Greater flexibility in an organisation can accommodate better ways of doing things. Therefore, greater flexibility in organisational structure can result in increased knowledge creation and help to optimise the expertise of knowledge workers (Choi \& Lee, 2003).
Knowledge creation is the exclusive output of an organised individual human activity (Lee \& Cole, 2003.) We cannot remove it from the information in the organisational database (Laise et al., 2005).

\section{Transferring knowledge}

Many organisations are increasingly using knowledge workers, mainly because of the lack of in-house expertise, poor knowledge worker retention and difficulties with keeping up with changing technologies (Adamson, 2005).

However, for an organisation to optimise the expertise of its knowledge workers, it must transfer knowledge from one knowledge worker to another successfully (Dong-Gil, Kirsh \& King, 2005). Creating and transferring knowledge is the basis for optimising their expertise (Brachos et al., 2007) and involves the constant transfer from tacit knowledge to explicit knowledge and back again in an increasing spiral (Sanders, 2005).

Transferring knowledge benefits an organisation more than knowledge itself because knowledge is primarily about context-specific features (Choi \& Lee, 2003). The key to transferring knowledge is that it is relational because transfers often occur between knowledge workers in the same setting (Nadler, Thompson \& Van Boven, 2003; Williams, 2006).

The ability to use existing knowledge internally in an organisation is vital to optimising the expertise of knowledge workers (Janz \& Prasarnphanich, 2003; Kodama, 2006; Thomas \& Hult, 2003). An important method of using existing knowledge is through transferring existing knowledge amongst knowledge workers in the organisation (Watson \& Hewett, 2006). Knowledge transfers when learning happens and when the recipient understands its context, the implications associated with the knowledge and the knowledge worker can apply it effectively (Watson \& Hewett, 2006).

\section{Sharing knowledge}

For an organisation to be sustainable in today's business environment, it must optimise the expertise of its knowledge workers. It must also share its knowledge if it is to use its core competencies (Hicks et al., 2006).

To be successful, an organisation must develop the ability to capture the knowledge it acquired in one part of an organisation and make it available to the rest of the organisation (Arnulf, Dreyer \& Grenness, 2005). The most important aspects of creating new knowledge are sharing it and reflective learning on the job. Here workers may modify the original idea progressively until a shared perspective emerges and they share it effectively in face-to-face interactions (Merx-Chermin \& Nijhof, 2005).

How well an organisation shares its knowledge has a direct effect on optimising the expertise of its knowledge workers. Organisations can facilitate it through several strategies. They include using technology appropriately, introducing 
incentive schemes for sharing knowledge, as well as cultivating and establishing innovation incubators (Coakes \& Smith, 2007). Innovation incubators comprise knowledge workers whose high levels of knowledge and skills are a foundation for the work outcome (Davison \& Blackman, 2005), where the knowledge workers active in the innovation process benefit from the collective effort (Koster, Stokman, Hodson \& Sanders, 2007). Effective innovation incubators encourage interaction and dialogue between knowledge workers and facilitate the creation of different points of view that may lead to new products, services and ways of working.

\section{Communicating knowledge}

In the current competitive environment, knowledge is vital for the survival of an organisation. For knowledge to become an asset, the organisation must communicate and share it within the organisation (Albina et al., 2004).

Communication plays a crucial role in the process of optimising the expertise of knowledge workers as it contributes to socialisation and assists in building and maintaining the social capital that is embedded in an organisation's relationships (Joshi, Sarker \& Sarker, 2007).

An organisation can transfer its knowledge in embedded relationships through a person-to-person approach to communication (Greiner et al., 2007). When people exchange knowledge to help to create new knowledge, the communication process is more of a conversation as knowledge passes back and forth between knowledge workers (Jackson, 2007).

Successful communication means that knowledge workers are informed about the progress of the activities they are directly involved in as it passes through an organisation. Knowledge workers also need to know what is happening throughout the organisation to enable them to respond appropriately (Barratt, 2004).

Communication plays a vital role in entrenching knowledge management as a strategic focus area in an organisation. Therefore, the organisation needs a structured communication plan to ensure adequate communication about how it manages knowledge (Du Plessis, 2007). The structured communication plan must recognise the critical role of context and the interaction between the various stakeholders involved in the process of optimising the expertise of knowledge workers (Joshi et al., 2007).

The main research questions are:

- What are the organisational design elements organisations need to optimise the expertise of knowledge workers?

- What supportive organisational competencies do organisations need to optimise the expertise of knowledge workers?

The next part of the article outlines the research design. The findings of the study follow. The article concludes with a discussion of the findings and recommendations for managers and future research.

\section{Research design \\ Research approach}

The researcher chose qualitative research because it focuses on human experiences from a holistic, in-depth perspective and is well suited to exploring complex problems (Vishnevsky \& Beanlands, 2004).

The researcher used an interpretivist method to conduct the research. This approach acknowledges that meaning becomes clear through interaction and emphasises the importance of understanding the overall text of a conversation (Rubin \& Rubin, 1995). Researchers use this methodology broadly in qualitative evaluative research because it is particularly suited to intensive, small-scale research (Walker \& Dewar, 2000).

The methodology reflects the beliefs about knowledge and existence that arise from the values in the philosophic framework that the researcher will use. This research method also contains the theoretical framework that guides how it will progress and how the researcher will construct a particular type of knowledge (Caelli, Ray \& Mill, 2003).

The interpretivist approach offers possibilities for generating fresh insights because it can point out different facets of organisational phenomena and can produce markedly different and uniquely informative theoretical views of events (Alvarez, 2003).

The main researcher used an interpretivist framework to look for the frames that shape the meaning and anticipated that, working in this paradigm, the main researcher would be very sensitive to the role of context.

\section{Research strategy}

The main researcher used a case study for this research. Yin (2003) defines the case study research method as an empirical inquiry that investigates a contemporary phenomenon in its real-life context. This is when the boundaries between phenomenon and context are not clear and where the researcher uses many sources of evidence.

The main researcher integrated the themes derived from the focus groups and compared them with the literature. He generated a universal result for the case participants. It was consistent with the modernistic interpretivist strategy that the researcher followed (Munsamy \& Venter, 2009).

\section{Research method}

\section{Research setting}

The main researcher conducted the research in a shared services centre. The SSC was established to centralise the back office functions of human resources, procurement, finance, technology support and internal audit in a single provincial department. The SSC had been in existence for almost ten years. 
The main researcher was a manager at the organisation, was familiar with the culture of the company and could identify verification processes to establish the validity of comments the respondents made. Peer scrutiny eliminated possible research bias.

\section{Entrée and establishing researcher roles}

The main researcher made a submission to the chief executive officer of the shared service centre requesting permission to conduct the research at the organisation. Once he received approval to proceed with the research, the researcher asked the human resources department of the SSC to generate a report to assist in selecting a sample.

The report contained all personal information, including the highest qualification the employees had obtained. The researcher refined the report further and omitted employees without university degrees because a degree was a qualifying criterion for a knowledge worker in this research.

The refined list contained the names of 157 knowledge workers. They became the employees at the SSC that the researcher invited to join the focus group sessions.

Once the researcher had identified the respondents, he obtained permission from the organisation's gatekeepers. Gatekeepers are people who control matters of interest (Glesne, 1999). Sometimes they may be personal assistants or people who can influence decisions about whether a respondent may participate in research or not.

The researcher monitored the relationship with gatekeepers because they could shape the direction of the research (Neuman, 2003). The main researcher compiled electronic mail messages to invite knowledge workers from the refined list to participate in the focus group sessions. Whenever possible, the researcher invited knowledge workers from the same business unit to different focus group sessions. He did this to limit opportunities for the views of subordinate respondents to stifle those of senior employees (Branigan, 2000).

The researcher explained the research process to the participants. The researcher obtained the informed consent of participants and participation was voluntary. He kept information confidential.

\section{Sampling}

The researcher used purposive sampling because it relies on the judgement of the researcher when selecting cases. The researcher selected cases with a specific purpose. This was to increase the understanding of selected respondents and to develop theories and concepts (Babbie \& Mouton, 2001; Neuman, 2003).

Instead of choosing a sample that represents a given population, the researcher included respondents with experience of the research proposals (Neuman, 2003). In qualitative research, the sample size is rarely predetermined and the researcher included as many respondents as was necessary to gain a comprehensive understanding of the research questions (Vishnevsky \& Beanlands, 2004).

Therefore, the researcher invited 157 knowledge workers to participate in the research. The researcher selected these respondents because they were qualified, had practical experience (Cooper, 2006) and could provide the information the researcher needed.

Of these knowledge workers, 25 participated in the focus groups sessions. Table 1 gives the demographic profile of the respondents.

Table 1 shows that the respondents were mostly male and held a degree. Most of the respondents had more than five years of experience as knowledge workers.

\section{Data collection}

The main researcher collected data during focus groups sessions. In these sessions, respondents participated in a guided discussion to enable the researcher to question several respondents systematically and simultaneously on a defined area of interest (Neuman, 2003). The aim of the focus group sessions was to uncover a range of perceptions about the knowledge worker and to enable people to share experiences relevant to the research proposals (Woodring, Foley, Rado, Brown \& Hamner, 2006).

In this research, the focus group sessions comprised three to five respondents to increase the quality of the data (Twinn, 1998). The researcher ran six focus group sessions.

TABLE 1: Demographic information of participan.

\begin{tabular}{|c|c|c|c|}
\hline Respondent & Male/Female & Qualification & Years of experience \\
\hline 1 & Female & Degree & 5 \\
\hline 2 & Male & Degree & 10 \\
\hline 3 & Male & Degree & 26 \\
\hline 4 & Male & Degree & 30 \\
\hline 5 & Male & Degree & 30 \\
\hline 6 & Female & Degree & 6 \\
\hline 7 & Female & Degree & 4 \\
\hline 8 & Male & Degree & 25 \\
\hline 9 & Male & Degree & 7 \\
\hline 10 & Male & Degree & 25 \\
\hline 11 & Female & Degree & 7 \\
\hline 12 & Male & Degree & 17 \\
\hline 13 & Male & Degree & 15 \\
\hline 14 & Male & Degree & 4 \\
\hline 15 & Female & Degree & 6 \\
\hline 16 & Female & Degree & 11 \\
\hline 17 & Female & Degree & 14 \\
\hline 18 & Female & Degree & 24 \\
\hline 19 & Male & Degree & 10 \\
\hline 20 & Male & Degree & 34 \\
\hline 21 & Male & Degree & 17 \\
\hline 22 & Female & Degree & 5 \\
\hline 23 & Female & Degree & 6 \\
\hline 24 & Male & Degree & 8 \\
\hline 25 & Female & Degree & 3 \\
\hline
\end{tabular}




\section{Data recording and storing}

The main researcher made a full record of the focus group sessions soon after they occurred to control bias and produce reliable data for analysis (Saunders, Lewis \& Thornhill, 2003).

The researcher took notes and was able to record reactions to relevant information respondents gave to signal to them the importance of what they were saying or to pace the focus group sessions (Rubin \& Rubin, 1995).

Notes the researcher took after the focus group notes allowed him to monitor the process of collecting data and to analyse the information.

The researcher forwarded copies of the transcripts to the respondents to allow them to comment on the accuracy of the content.

\section{Data analysis and interpretation}

Interpretive research is not designed to gather 'simple' data or to 'work with the data' in elementary ways. Therefore, the researcher started with a set of data, like a transcribed focus group session (Lecompte, 1994).

It was not feasible to transcribe entire tape recordings. Nevertheless, the researcher made every effort to record the type of detailed information he needed to analyse conversation.

The researcher began by tidying up the information he had collected and categorising the data. This allowed him to establish whether anything was missing and to justify the alterations to the original implementation scheme (Lecompte, 1994). This process also allowed the researcher to alter themes and sub-themes or relationships in the rearranged data as he searched for meaning from the data set (Rubin \& Rubin, 1995; Saunders et al., 2003). The researcher then analysed the data to identify themes and sub-themes. This was a good way of creating an initial framework to attach an analysis of the research outcomes.

The researcher compared the initial framework against a revised data matrix to determine where each cluster of data ultimately fitted (Lecompte, 1994). He compared data within the themes and sub-themes to look for variations and nuances in meanings (Rubin \& Rubin, 1995). This was also a good way of identifying the types of research outcomes he might have to produce after the evaluation (Lecompte, 1994).

The researcher was able to keep an up-to-date definition of each theme and sub-theme to maintain consistency when assigning units of data as the collection of data progressed (Saunders et al., 2003). The researcher organised the data to enable the reader to identify themes and sub-themes easily (Rubin \& Rubin, 1995).

While analysing the data, the researcher counted how many times the respondents repeated an issue to establish trends (Seidman, 1991).
When gathering the data, the researcher provided access to information to allow him to work with the data in different ways, using different means of analysis (Henning, 2004).

\section{Strategies used to ensure quality data}

The credibility of the researcher is particularly important in qualitative research because the researcher is the main instrument of collecting and analysing data (Shenton, 2004).

The researcher ensured the quality and rigour of this research by adhering to the criteria that follow (see Denzin \& Lincoln, 2003; Yin, 2003):

- reliability

- internal validity

- cultural familiarity

- honesty of respondents

- iterative questioning

- peer scrutiny

- the main researcher's reflective commentary

- transferability

- dependability

- conformability.

In this research, reliability meant showing that other researchers could repeat the method of collecting data to yield the same results. It also addressed the accuracy of the research method the researcher used when collecting data. Therefore, the researcher attempted to record the data fully and to explain the methods of collecting and analysing the data in detail.

To achieve conformability, the main researcher showed that the findings that emerged from the data were not his own (Shenton, 2004). He made every effort to capture the data as reliably as possible after the tape recordings had been transcribed.

During iterative questioning, the researcher returned to matters that participants had raised earlier and extracted the relevant data by rephrasing questions.

Where contradictions appeared and the truth was questionable, the researcher discarded the data (Shenton, 2004). To improve honesty, every respondent the researcher approached to participate in the research could refuse. This ensured that the data collection sessions included only those respondents who were genuinely willing to take part and were prepared to offer information freely. At the beginning of each session, the researcher encouraged respondents to be candid.

\section{Reporting}

The main researcher reported the findings using the modernist qualitative research approach. Therefore, the researcher looked for probabilities or support for arguments about the likelihood that a conclusion applies in a specific situation (Denzin \& Lincoln, cited in Munsamy \& Bosch Venter, 2009). 
He compared his findings with the literature.

\section{Findings}

Table 2 gives the responses that emerged from the focus group sessions. The table gives the frequency with which themes emerged. The researcher identified 12 themes from the combined responses of the participants.

Table 2 shows that 'structure', 'optimise expertise' and 'knowledge management' were the themes that occurred most often and that 'knowledge' and 'knowledge sharing' occurred the least often.

The article will discuss the themes according to the framework presented in the literature review.

\section{Theme 1: Organisational design elements}

The first theme includes 'structure', 'culture' and 'codification system'. Overall, the findings suggested that the shared services centre is not designed to enable the structure, culture and codification system to optimise the expertise of knowledge workers. Respondents expressed the opinion that the service centre used them for their ability to resolve crises on a day-to-day basis and not for their applied expertise.

Respondents indicated that they are able to share knowledge only through personal relationships with other knowledge workers.

Furthermore, respondents seemed to recognise that they lose opportunities to improve performance because there were no processes to enable knowledge workers to identify specific expert knowledge that the centre could use to create new knowledge.

\section{Subtheme: Structure}

Structure was the theme that emerged most often from the responses (47 times). Some respondents asserted that the structure actually prevented the exchange of tacit knowledge. They expressed a high degree of frustration at the existence of silos and felt that they were unable to interact outside of their respective silos.

TABLE 2: Themes deduced from the respondents.

\begin{tabular}{ll}
\hline Themes & Frequency \\
\hline Structure & 47 \\
Optimise expertise & 33 \\
Knowledge management & 28 \\
Organisational design & 26 \\
Codification system & 24 \\
Competitive advantage & 24 \\
Culture & 18 \\
Knowledge transfer & 13 \\
Knowledge communication & 10 \\
Knowledge creation & 8 \\
Knowledge sharing & 7 \\
Knowledge & 7 \\
\hline
\end{tabular}

Another consequence of respondents operating within silos was that they had little understanding of the organisation around them:

'In the SSC, there are 1,400 people working but only about 20 are able to share with others and mostly on an informal basis. There is no mechanism. We work in silos. The problem is that people don't want to develop themselves and you can't share with someone who doesn't want to learn. The structure does not allow people to draw from each other.'

(Respondent 16)

Another knowledge worker offered support:

'There is nothing that helps the flow of knowledge to others; we have to force it by sharing with those we know well. The structure has a major role to play because the people are not managed. The structure is not able to solve a big problem, which is a loss of skilled experience employees.'

(Respondent 4)

\section{Subtheme: Culture}

The culture of the SSC seems to discourage creativity because it values only narrowly defined functional output. Respondents spoke of how managers ignore new ideas, thus sending a clear message that developing new ideas is not a feature of the culture at the SSC. The culture does not support the view that an organisation should value the ideas and knowledge that knowledge workers create:

'We don't have that kind of culture whereby you share with people, whether it's an email or an attachment.'

(Respondent 7)

\section{Subtheme: Codification}

The responses of the participants make it clear that the knowledge created in the SSC is not codified and that the organisation is unaware of the value of codifying the knowledge of knowledge workers as a way of eliminating recurring problems. The organisation does not convert the implicit experiences of its knowledge workers into explicit knowledge so that the new knowledge does not become available for others to use when dealing with similar problems:

'... the only formal information sharing that I can speak about in our structure is the meetings.'

(Respondent 11)

and

'There is no formal process where you write down what you've found and pass it on to other people.

(Respondent 6)

\section{Theme 2: Organisational competencies for optimising the expertise of knowledge workers}

The responses of the participants made it clear that knowledge created at the SSC is not shared with other knowledge workers and that it does not use the output of the knowledge workers to improve business processes. Respondents noted that they had learnt much in dealing with the daily problems that keep arising. They also revealed that there are no mechanisms for sharing the knowledge they had created, nor 
are there any processes for integrating the knowledge into business processes as ways of eliminating the problems.

\section{Subtheme: Knowledge management}

Knowledge management is the theme that occurred third most often. Participants mentioned it 28 times. From the responses, the researcher gathered that the SSC does not make the most of its knowledge assets. Respondents revealed that it was difficult for them to share their knowledge with other knowledge workers because the centre continually focused on organisational activities rather than on efforts to make the most of its knowledge assets. Respondents revealed that this emphasis on activities and not on optimising knowledge assets resulted in real losses when a knowledge worker left the organisation without sharing or transferring specific knowledge:

\begin{abstract}
'... there is nothing formally that compels me to share my knowledge. Even when you have a problem and you know who can assist you, you won't get people to put in the effort to come and sit with you and help you. So in many instances it's a crisis that will drive us to work together and share what we know. The driver of that process or document or programme - if that person leaves then the whole thing crashes.'
\end{abstract}

(Respondent 2)

\section{Subtheme: Knowledge transfer}

From the responses of the participants, it seems that the SSC's focus is not on the productive use of knowledge-based resources. Respondents revealed that the organisation does not have a process that effectively moves knowledge from one knowledge worker to another. This weakness could be harmful to the organisation because respondents believed that, if key knowledge workers left the organisation, incomplete projects would fail because there was no transfer of knowledge:

\begin{abstract}
'It's hard for me to actually share with my colleagues because in my situation I focus on problems that arise and I have to solve those problems in as short a time frame as possible. Some other guys might have knowledge about the problems we might be experiencing and how to go about sharing that knowledge, I think that forum has not really been utilised to its fullest. You will find that there is no continuity because people who did the design leave and six months later no one is actually sure as to how implementation was supposed to happen.'
\end{abstract}

(Respondent 1)

\section{Subtheme: Knowledge communication}

From the responses of the participants, it was clear that the SSC does not provide support functions that enable knowledge workers to exchange knowledge. Therefore, there is duplication of effort and the SSC does not use its resources fully. Respondents complained that they are not able to communicate the knowledge they have created. Therefore, they are unable to benefit from the knowledge another knowledge worker has created:

'Everyone is so focused on business that I feel I cannot tell them what I know because I will be attacked. I do the job as I am supposed to do, as I know from my experience. But I don't tell everyone. There is no need for me to talk to other employees about what I know.

(Respondent 5)

\section{Other subthemes: Knowledge creation, knowledge sharing and knowledge}

'Knowledge creation', 'knowledge sharing' and 'knowledge' were the themes the participants mentioned least often.

However, this does not mean that these themes are unimportant organisational competencies. It seems that the SSC does not have a mechanism to enable the organisation to capitalise on the ability of knowledge workers to combine existing information, knowledge and ideas. Respondents decided that other knowledge workers have the specific knowledge that can assist them to deal with a problem. However, this previously created knowledge is not available, as it is not embodied in the organisation.

It seems that the SSC does little to determine what knowledge already exists about a problem. Respondents revealed that they were aware of existing knowledge, but that this knowledge was not available to them. They also expressed a degree of frustration at policies and procedures that have not kept up with current knowledge:

'Some other guys might have knowledge about the problems we might be experiencing and how to go about sharing that knowledge. I think that forum has not really been utilised to its fullest. You will find that there is no continuity because people who did the design leave and six months later no one is actually sure as to how implementation was supposed to happen.'

(Respondent 2)

It seems that the SSC does not make it easy for knowledge workers to share new knowledge by combining existing knowledge. This would enable the organisation to become better at using existing knowledge. Respondents revealed that formal meetings were the only opportunities they had to share knowledge. However, the meetings are structured and restricted in terms of who is invited. Therefore, they were not opportunities for reflective learning.

Based on the results, the researcher deduced that the SSC does not optimise the expertise of knowledge workers (respondents mentioned this 32 times). It does not share the knowledge they create with knowledge workers in other divisions and does not use their output to improve business processes.

Respondents noted that they had learnt much in dealing with the daily problems that keep arising, but that the centre did not give them the opportunity to integrate their knowledge into business processes.

The centre recognises the knowledge workers' tacit knowledge and its application to keep the SSC afloat by dealing effectively with the issues that keep cropping up. However, the organisation does not value the expertise the knowledge workers apply to solving the problems. Knowledge workers develop novel ideas to deal with problems, but there is no process to develop these ideas into solutions. 
There are no mechanisms for sharing the knowledge they created nor are there any processes for integrating the knowledge into business processes as ways of eliminating the problems.

Consequently, in terms of competitive advantage (a theme the knowledge workers mentioned 24 times), the organisational design of the SSC does not contain the basics for optimising the expertise of knowledge workers, which is vital for creating competitive advantage. The organisation seems to focus more on using the knowledge workers than it is on gaining competitive advantage from applying their expertise.

The SSC neglects to develop its personal, organisational and core capabilities. It seems that the role of managers is to assign a knowledge worker to deal with problems that recur and to resolve the problems as quickly as possible.

\section{Discussion}

The main objective of this research was twofold. Firstly, the researcher aimed to explore the organisational design elements that help to optimise the expertise of knowledge workers. Secondly, he aimed to determine what supportive organisational competencies the service centre needed to optimise the expertise of knowledge workers.

This research makes an important contribution to identifying those organisational design elements and supportive organisational competencies that organisations need to optimise the expertise of knowledge workers.

The researcher proposes an integrated framework to combine organisational design elements and supportive competencies if the organisation is to gain sustainable competitive advantage.

The findings on the objectives of this research follow.

\section{Research objective 1: To explore the organisational design elements for optimising the expertise of knowledge workers}

The findings showed that the SSC is not designed to enable the structure, culture and codification system to optimise the expertise of knowledge workers.

In particular, the organisational structure of the SSC seemed problematic. Knowledge workers mentioned this point 47 times. They were frustrated that they operate in silos and that the current structure prevents the exchange of tacit knowledge. Consequently, knowledge workers were unable to locate relevant information and expertise outside their 'silo'. This confirms the findings of Sveiby and Simons (2002). A consequence of working in silos is that knowledge workers do not know what is happening elsewhere in the SSC. Therefore, efforts are duplicated and mistakes repeated. The silo mentality has developed into a climate of silence where knowledge workers are more inclined to handle problems in their own functional areas, ignoring the difficult interaction between the silos. As a result, knowledge workers tend to discuss these issues only in private, in ways that reinforce the climate of dissatisfaction. This guarantees that they remain confidential and, therefore, not discussed. The findings confirmed the research of Hicks et al. (2006), who state that an organisation cannot use knowledge effectively if its knowledge workers cannot locate or access the knowledge they need.

In addition, thefindingsshowed that thecurrentorganisational culture and codification systems do not optimise the expertise of knowledge workers. The respondents mentioned, amongst others, that the culture does not support the view that the ideas and knowledge, which knowledge workers create, are valuable to the organisation.

The findings contradict those of Lucas and Ogilvie (2006). They propose that an organisation should have a strong set of core values and norms that encourage creating and sharing knowledge and the active participation of knowledge workers in the process.

With regard to codification, the findings showed that the service centre does not convert the implicit experiences of its knowledge workers into explicit knowledge so that the new knowledge becomes available for others to use when dealing with similar problems.

The findings contradict Davies et al. (2005). They suggest that the general purpose of codifying knowledge is to ensure greater standardisation and organisation-wide dispersal of knowledge.

Overall, the findings confirm Kenney's (2006) study on the relationship between the organisation's ability to operate effectively and how well it optimises the expertise of knowledge workers.

\section{Research objective 2: To determine which supportive organisational competencies are needed to optimise the expertise of knowledge workers}

The five supportive organisational competencies the respondents identified in this research were 'knowledge', 'managing knowledge', 'creating knowledge', 'sharing knowledge' and 'communicating knowledge'. This is consistent with the literature.

In general, the findings showed that managing knowledge remains a challenge for the SSC, because the organisation does not try to optimise its knowledge assets. Consequently, there are no mechanisms for sharing the knowledge the knowledge workers create, nor are there any processes for integrating the knowledge into business processes as ways of eliminating problems. 
The findings contradict Merx-Chermin and Nijhof (2005). They propose that the most important aspect of creating new knowledge is sharing it and reflective learning on the job. Furthermore, the findings also contradict DongGil et al. (2005), who stated that, for an organisation to optimise the expertise of its knowledge workers, it must transfer knowledge from one knowledge worker to another successfully.

As part of an effort to optimise knowledge assets, the organisation must design a knowledge management system that enables it to use knowledge effectively and that allows knowledge workers to find high-quality content easily without feeling overwhelmed (Holste \& Fields, 2005; Poston \& Speier, 2005).

In the light of these findings, the researcher proposes the framework that follows to optimise the expertise of knowledge workers in the shared services centre effectively.

According to this proposed framework, two strata mobilise an organisation. The business systems stratum contains the design elements and the knowledge base stratum contains the supportive organisational competencies.

The business system contains the organisational structure and its business processes. It is where the organisation carries out its routine operations. The business systems stratum enables an organisation to perform at an increasingly improved level of performance as it incorporates the expertise of knowledge workers into business processes and routine operations systematically.
The optimised expertise of knowledge workers, when integrated into the business systems stratum, becomes the base, or platform, for creating further knowledge.

The knowledge base stratum includes 'knowledge', 'knowledge management', 'knowledge sharing', 'knowledge communication' and 'knowledge transfer'. The knowledge base stratum supports the business systems stratum, thereby enabling the organisation to optimise the expertise of its knowledge workers.

For an organisation to optimise the expertise of its knowledge workers, it must develop supportive organisational competencies. They will help to create, share and embed the expertise of knowledge workers with the business processes and routine operations of the organisation. In this arrangement, the knowledge base stratum (software) acts on the business systems stratum (hardware) and enables the organisation to perform at an increasingly improved level as it optimises and integrates the expertise of the knowledge workers with business processes and routine operations.

Therefore, this framework introduces a mechanism that makes it possible for an unrelenting interaction between the expertise of knowledge workers, business processes and the routine operations of an organisation to improve performance continuously.

An effective design will lead to a process of assembling and fine-tuning an organisation's design to create and sustain competitive advantage (see Botha, 2000; Jarvenpaa \& Staples, 2001; Russo \& Harrison, 2005).
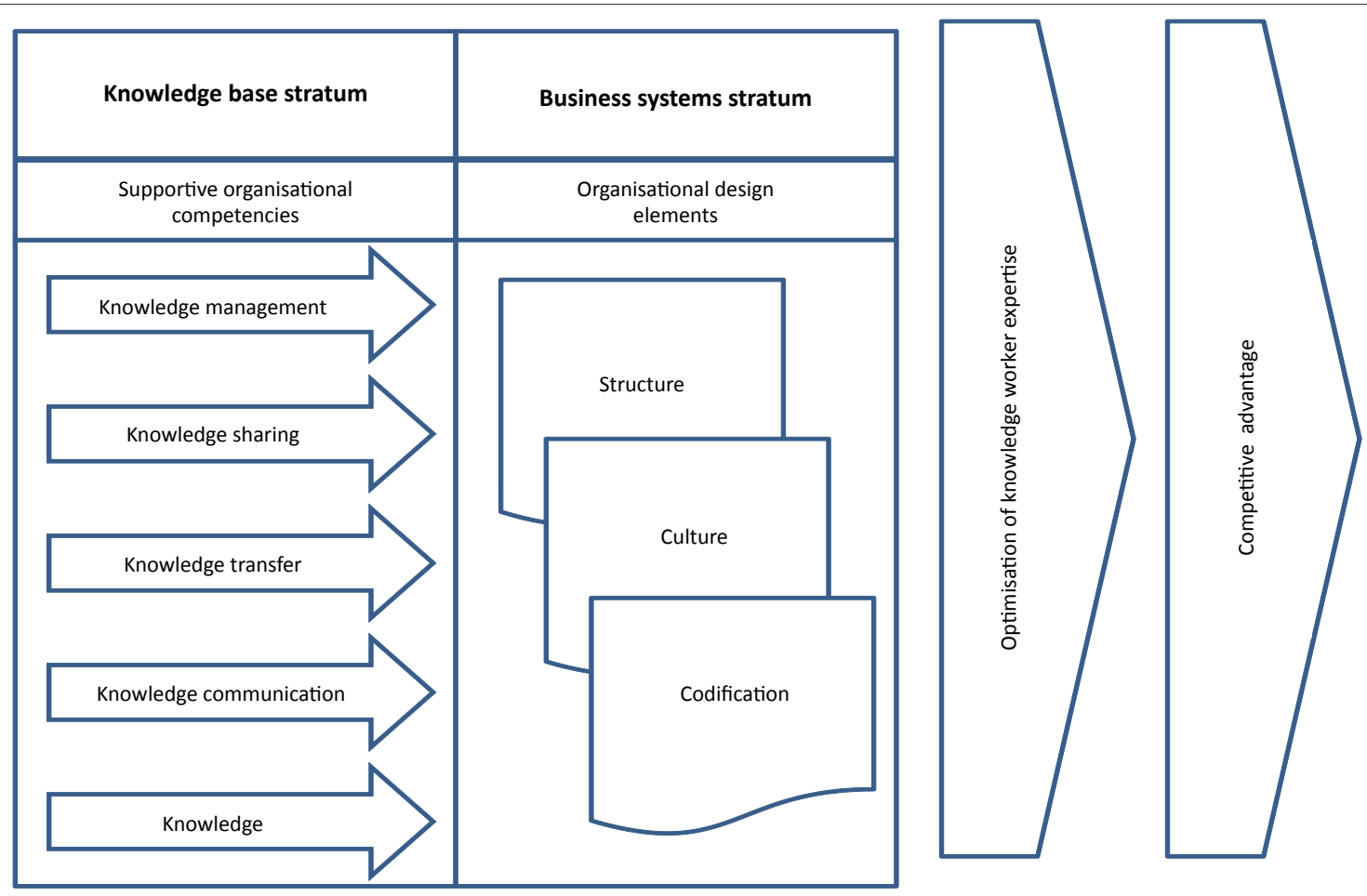

FIGURE 1: A framework for optimising the expertise of knowledge workers. 


\section{Implications and recommendations for managers}

This research adds to the theoretical debate on the design and supportive organisational competencies to optimise the expertise of knowledge workers. It also contributes by providing a framework for examining organisational design and the supportive organisational competencies that organisations need.

Based on the findings of the research, the researcher recommends that managers introduce an unremitting interplay between the expertise of knowledge workers, business processes and the routine operations of an organisation to improve performance continuously.

If they use innovation incubators effectively, managers will allow an increasing amount of knowledge worker tacit knowledge to fall under the control of the organisation. Managers should also introduce processes that promote sharing knowledge and integrating new knowledge with business processes and routine operations in order to optimise the expertise of knowledge workers.

Finally, managers should introduce a system where improved business processes and routine operations become the impetus for further refinement in the innovation incubators.

\section{Limitations of the research}

This research had some limitations. The researcher used a case study. This meant that he collected information from a small sample in a specific research setting. Therefore, the findings cannot be generalised to other research settings.

\section{Suggestions for further research}

Research to determine which information technologies can provide access to other domains of knowledge and promote knowledge worker innovation is needed. Research to determine how an organisation can provide a knowledge worker with a suitable career path will assist.

The research should focus on how structural arrangements can satisfy the career aspirations of knowledge workers. It would be valuable to carry out extensive research to determine what motivates knowledge workers so that organisations can understand this key element of human capital better. The research should include their value systems.

\section{References}

Adamson, I. (2005). Knowledge Management - The Next Generation of TQM? Total Quality Management, 16, 987-1000. doi:10.1080/14783360500163177

Akbar, H. (2003). Knowledge Levels and their Transformation: Towards the Integration of Knowledge Creation and Individual Learning. Journal of Management Studies, 40, 1997-2021. doi:10.1046/j.1467-6486.2003.00409.x

Albina, V., Garavelli, A., \& Gorgoglione, M. (2004). Organization and technology in knowledge transfer. Benchmarking: An International Journal, 11, 584-600.

Alsene, E. (2007). ERP systems and the coordination of the enterprise. Business Process Management Journal, 13, 417-432. doi:10.1108/14637150710752326

Alvarez, S. (2003). Towards an interpretative integrative framework to conceptualise social processes in large information systems implementations. Information Technology for Development, 10, 233-247. doi:10.1002/itdj.1590100403
Alvesson, M., Karreman, D., \& Swan, J. (2002). Departures Form Knowledge and/ or Management in Knowledge Management Management Communication Quarterly, 16, 282-291. doi:10.1177/089331802237242

Ansari, M.A., Hung, D.K.M., \& Aafaqi, R. (2007). Leader-member exchange and attitudinal outcomes: role of procedural justice climate. Leadership \& Organization Development Journal, 28, 690-709.

Arnulf, J., Dreyer, H., \& Grenness, C. (2005). Trust and knowledge creation: how the dynamics of trust and absorptive capacity may affect supply chain management development projects. International Journal of Logistics: Research and Applications, 8, 225-236.

Babbie, E., \& Mouton, J. (2001). The practice of social research. Cape Town: Oxford University Press.

Ballantine, J., \& McCourt Larres, J. (2007). Cooperative learning: a pedagogy to improve students generic skills. Education + Training, 49, 126-137.

Barber, F., \& Strack, R. (2005). The Surprising Economics of a 'People Business'. Harvard Business Review, 83, 80-90.

Barratt, M. (2004). Understanding the meaning of collaboration in the supply chain. Supply Chain Management: An International Journal, 9, 30-42. doi:10.1108/13598540410517566

Boder, A. (2006). Collective intelligence: a keystone in knowledge management Journal of Knowledge Management, 10, 81-93. doi:10.1108/13673270610650120

Bogdanowicz, M., \& Bailey, E. (2002). The value of knowledge and the values of the new knowledge worker: generation $X$ in the new economy. Journal of European Industrial Training, 26, 125-129. doi:10.1108/03090590210422003

Botha, D.F. (2007). Rethinking the knowledge bearing capacity of e-Business systems. South African Journal of Business Management, 38, 37-43.

Botha, D.F. (2000). A conceptional framework for the management of knowledge in a knowledge-based enterprise. South African Journal of Business Management 31, 141-152.

Brachos, D., Kostopoulos, K., Soderquist, K., \& Prastacos, G. (2007). Knowledge effectiveness, social context and innovation. Journal of Knowledge Management 11, 31-44. doi:10.1108/13673270710819780

Branigan, A. (2000). Using focus groups to evaluate health promotion interventions. Health Education, 100, 261-268. doi:10.1108/09654280010354887

Bryan, L., \& Joyce, C. (2005). The 21st-century organisation. McKinsey Quarterly, 24-33.

Caelli, K., Ray, L., \& Mill, J. (2003). 'Clear as Mud': Toward Greater Clarity in Generic Qualitative Research. International Journal of Qualitative Methods, 2, 1-23.

Choi, B., \& Lee, H. (2003). Knowledge Management Enablers, Process, and Organizational Performance: An Integrative View and Empirical Examination. Journal of Management Information Systems, 20, 179-228.

Coakes, E., \& Smith, P. (2007). Developing communities of innovation by identifying innovation champions. The Learning Organization, 14, 74-85. doi:10.1108/09696470710718366

Cooper, D. (2006). Knowledge Workers. Canadian Business, 79, 1-2.

Covey, S.R. (2004). The 8th Habit From Effectiveness To Greatness. London: Simon \& Schuster UK Ltd.

Danese, P., \& Romano, P. (2004). Improving inter-functional coordination to face high product variety and frequent modifications. International Journal of Operations \& Production Management, 24, 863-885. doi:10.1108/01443570410552090

Davies, J., Subrahmanian, E., \& Westerberg, A. (2005). The global and the local in knowledge management. Journal of Knowledge Management, 9, 101-112. doi:10.1108/13673270510582992

Davison, G., \& Blackman, D. (2005). The role of mental models in innovative teams. European Journal of Innovation Management, 8, 409-423.

Denzin, N.K., \& Lincoln, Y.S. (2003). The landscape of qualitative research. (2nd edn.). Thousand Oaks: Sage.

Dong-Gil, K., Kirsh, L.J., \& King, W. (2005). Antecedents of Knowledge Transfer From Consultants to Clients in Enterprise System Implementation. MIS Quarterly, 29, 59-85.

Drejer, A., \& Sorensen, S. (2002). Succeeding with souring of competencies in technology-intensive industries. Benchmarking: An International Journal, 9 , technology-ir.

Drucker, P.F. (1999). Management Challenges for The 21st Century. Massachusetts: Butterworth-Heinemann.

Du Plessis, M. (2007). Knowledge management: what makes complex implementations successful? Journal of Knowledge Management, 11, 91-101. doi:10.1108/13673270710738942

Duignan, R. (2007). Employee perceptions of recent work environment changes in Japan. Personnel Review, 36, 440-456. doi:10.1108/00483480710731365

Edvardsson, B. (2003). Quality in the work environment: a prerequisite for success in new service development. Managing Service Quality, 13, 148-163. doi:10.1108/09604520310466851

Glesne, C. (1999). Becoming qualitative researchers: an introduction. New York: Addison Wesley Longman, Inc.

Gold, A., Malhotra, A., \& Segards, A. (2001). Knowledge Management: An Organizational Capabilities Perspective. Journal of Management Information Systems, 18, 185-214.

Grandori, A., \& Soda, G. (2006). A Relationship Approach to Organizational Design Industry and Innovation, 13, 151-172. doi:10.1080/13662710600684316

Greiner, M., Böhmann, T., \& Krcmar, H. (2007). A Strategy for Knowledge Management. Journal of Knowledge Management, 11(6), S. 3-15 
Hall, M. (2006). Knowledge management and the limits of knowledge codification. Journal of Knowledge Management, 10, 117-126. doi:10.1108/13673270610670894

Hamel, G., \& Prahalad, C.K. (2005). Strategic Intent. Harvard Business Review, 83, $61-76$

Hammer, M., Leonard, D., \& Davenport, T. (2004). Why Don't We Know More About Knowledge? MIT Sloan Management Review, 45, 14-18

Hasgall, A., \& Shoham, S. (2008). Knowledge processes: from managing people to managing processes. Journal of Knowledge Management, 12, 51-62. to managing processes. Journal

Henning, E. (2004). Finding your way in qualitative research. Pretoria: Van Schaik Publishers.

Hicks, R., Dattero, R., \& Galup, S. (2006). The five-tier knowledge management hierarchy. Journal of Knowledge Management, 10, 19-31. doi:10.1108/13673270610650076

Holste, J.S., \& Fields, D. (2005). The Relationship of Affect and Cognition based Trust With Sharing and Use of Tacit Knowledge. Academy of Management, Best Conference Paper, B1-B6.

Hornstein, H.A., \& De Guerre, D.W. (2006). Bureaucratic Organisations Are Bad for Our Health. Ivey Business Journal, 1, 1-4.

Iverson, J., \& McPhee, R. (2002). Knowledge Management in Communities of Practice. Management Communication Quarterly, 16, 259-266. doi:10.1177/089331802237239

Jackson, T. (2007). Applying autopoiesis to knowledge management in organisations. Journal of Knowledge Management, 11, 78-91. doi:10.1108/13673270710752126

Jain, K., Nagar, L., \& Srivastava, V. (2006). Benefit sharing in inter-organizational coordination. Supply Chain Management: An International Journal, 11, 400-416. doi:10.1108/13598540610682417

Jantunen, A. (2005). Knowledge-processing capabilities and innovative performance: an empirical study. European Journal of Innovation Management, 8, 336-349. doi:10.1108/14601060510610199

Janz, B.D., \& Prasarnphanich, P. (2003). Understanding the Antecedents of Effective Knowledge Management: The Importance of a Knowledge-Centered Culture. Decision Sciences, 34, 351-384. doi:10.1111/1540-5915.02328

Jarvenpaa, S.L., \& Staples, D.S. (2001). Exploring Perceptions of Organizational Ownership of Information and Expertise. Journal of Management Information Systems, 18, 151-183.

Johanson, U., Martensson, M., \& Skoog, M. (2001). Measuring to understand intangible performance drivers. The European Accounting Review, 10, 407-437. doi:10.1080/09638180126791, doi:10.1080/09638180120081562

Joshi, K., Sarker, S., \& Sarker, S. (2007). Knowledge transfer within information systems development teams: Examining the role of knowledge source attributes. Decision Support Systems, 43, 322-335. doi:10.1016/j.dss.2006.10.003

Kenney, J.L., \& Gudergan, S.P. (2006). Knowledge integration in organizations: an empirical assessment. Journal of Knowledge Management, 10, 43-58. doi:10.1108/13673270610679354

Keskin, H. (2005). The Relationship Between Explicit and Tacit Oriented KM Strategy, and Firm Performance. The Journal of American Academy of Business, Cambridge, 7, 169-175.

Kirkwood, T., \& Pangarkar, A. (2003). Workplace learning - beyond the classroom. CMA Management, 10-12.

Kodama, M. (2006). Strategic Community: Foundation Of Knowledge Creation. Research - Technology Management, 49-58.

Koening, M. (1999). Education for Knowledge Mangement. Information Services \& Use, 19, 17-31.

Koners, U., \& Goffin, K. (2007). Manager's perception of learning in new product development. International Journal of Operations \& Production Management, 27 49-68. doi:10.1108/01443570710714538

Koster, F., Stokman, F., Hodson, R., \& Sanders, K. (2007). Solidarity through networks: The effects of task and informal interdependence on cooperation within teams. Employee Relations, 29, 117-137.

LaDuke, B. (2005). Beyond Polanyi. Knowledge Management, 10-11.

Lai, M., \& Lee, M. (2007). Risk-avoiding cultures toward achievement of knowledge sharing. Business Process Management Journal, 13, 522-537. doi:10.1108/14637150710763559

Laise, D., Migliarese, P., \& Verteramo, S. (2005). Knowledge Organization design: A diagnostic tool. Human Systems Management, 24, 121-131.

Lebowitz, M.A. (2005). The Knowledge of a Better World. Monthly Review, 62-69.

Lecompte, M. (1994). Sensible Matchmaking: Qualitative Research Design and the Program Evaluation Standards. Journal of Experimental Education, 63, 117-129. doi:10.1080/00220973.1994.9943824

Lee, G.K., \& Cole, R.E. (2003). From a Firm-Based to a Community-Based Model of Knowledge Creation: The Case of the Linux Kernel Development. Organization Science, 14, 633-649. doi:10.1287/orsc.14.6.633.24866

Lee, R.G., \& Dale, B.G. (1998). Business process management: a review and evaluation. Business Process Management, 4, 214-225. doi:10.1108/14637159810224322

Levy, J. (2005). The Fourth Revolution. $T+D, 59,64-66$.

Lucas, L.M., \& Ogilvie, D.T. (2006). Things are not always what they seem: How reputations, culture, and incentives influence knowledge transfer. The Learning Organization, 13, 7-24. doi:10.1108/09696470610639103

Marouf, L. (2007). Social networks and knowledge sharing in organizations: a case study. Journal of Knowledge Management, 11, 110-125. doi:10.1108/13673270710832208
Martins, E.C., \& Terblanche, T. (2003). Building organisational culture that stimulates creativity and innovation. European Journal of Innovation Management, 6, 64-74. doi:10.1108/14601060310456337

Massey, A.P., Montoya-Weiss, M.M. (2006). Unraveling The Temporal Fabric Of Knowledge Conversion: A Model Of Media Selection. MIS Quarterly, 30, 99-114.

Massey, A., Montoya-Weiss, M., \& O'Driscoll, T. (2002). Performance-Centered Design of Knowledge-Intensive Processes. Journal of Management Information Systems, 18, 37-58.

McFadyen, M.A., \& Cannella, A.A. (2004). Social Capital And Knowledge Creation Diminishing Returns Of The Number And Strength Of Exchange Relationships. Academy of Management Journal, 47, 735-746. doi:10.2307/20159615

Meilich, O. (2005). Are Formalization and Human Asset Specificity Mutually Exclusive? Journal of American Academy of Business, 6, 161-169.

Merx-Chermin, M., \& Nijhof, W.J. (2005). Factors influencing knowledge creation and innovation in an organisation. Journal of European Industrial Training, 29, 135-147. doi:10.1108/03090590510585091

Munsamy, M., \& Bosch Venter, A. (2009). Retention factors of management staff in the maintenance phase of their careers in local government. SA Journal of Human Resource Management/SA Tydskrif vir Menslikehulpbronbestuur, 7(1), 1-9.

Muthusamy, S.K., \& White, M.A. (2005). Learning and Knowledge Transfer in Strategic Alliances: A Social Exchange View. Organizational Studies, 26, 415-441. doi:10.1177/0170840605050874

Nadler, J., Thompson, L., \& Van Boven, L. (2003). Learning Negotiation Skills: Four Models of Knowledge Creation and Transfer. Management Science, 49, 529-540. doi:10.1287/mnsc.49.4.529.14431

Neuman, W.L. (2003). Social Research Methods: Qualitative and Quantitative Approaches. Boston, MA: Pearson Education.

$\mathrm{Ng}$, P.T. (2004). The learning organisation and the innovative organisation. Human Systems Management, 23, 93-100.

Oliver, S., \& Kandadi, K. (2006). How to develop knowledge culture in organizations? A multiple case study of large distributed organizations. Journal of Knowledge Management, 10, 6-24. doi:10.1108/13673270610679336

Owen, J.M. (1999). Knowledge management and information professional. Information Services \& use, 19, 7-16.

Peltonen, T., \& Lamsa, T. (2004). 'Communities of Practice' and the Social Process of Knowledge Creation: Towards a New Vocabulary for Making Sense of Organizational Learning. Problems and Perspectives in Management, 249-262.

Pham, N.T. (2006). Facilitators of organizational learning in design. The Learning Organization, 13, 186-201. doi:10.1108/09696470610645502

Pham, N., \& Swierczek, F. (2006). Facilitators of organizational learning in design. The Learning Organization, 13, 186-201.

Pillania, R.K. (2005). New Knowledge Creation Scenarion in Indian Industry. Globa Journal of Flexible Systems Management, 6, 49-57.

Poston, R., \& Speier, C. (2005). Effective use of knowledge management systems: a process model of content ratings and credibility indicators. MIS Quarterly, 29, 221-245.

Prieto, I., \& Revilla, E. (2006). Learning capability and business performance: a nonfinancial and financial assessment. The Learning Organization, 13, 166-185. doi:10.1108/09696470610645494

Robertson, M., Scarbrough, H., \& Swan, J. (2003). Knowledge Creation in Professional Service Firms: Institutional Effects. Organization Studies, 24, 831-857. doi:10.1177/0170840603024006002

Rodriguez-Lluesma, C., \& Bailey, D.E. (2005). Broadening The Scope: Exploring Three Knowledge Distinctions. Academy of Management, Best Conference Paper, H1 H6.

Rowold, J., \& Hochholdinger, S. (2008). Effects of career-related continuous learning: a case study. The Learning Organization, 15, 45-57. doi:10.1108/09696470810842484

Rubin, H., \& Rubin, I. (1995). Qualitative Interviewing; The Art of Hearing Data. California: SAGE Publications Inc.

Russo, M., \& Harrison, N. (2005). Organisational Design and Environmental Performance: Clues from the Electronics Industry. Academy of Management Journal, 48, 582-593.

Sanders, D. (2005). Creation of New Knowledge. Defence \& security Analysis, 21 283-302. doi:10.1080/0743017052000344956

Saunders, M., Lewis, P., \& Thornhill, A. (2003). Research Methods for Business Students. England: Pearson Education Limited.

Seidler-de Alwis, R., \& Evi Hartmann, E. (2008). The use of tacit knowledge within innovative companies: knowledge management in innovative enterprises. Journal of Knowledge Management, 12, 133-147. doi:10.1108/13673270810852449

Seidman, I. (1991). Interviewing As Qualitative Research; A guide for Researchers in Education and the Social Sciences. New York: Teachers College Press.

Sharkey, L. (2006). Organization Integration Case Study: A Practical Approach to Drive Faster Results. Organizational Development Journal, 24, 44-54.

Shenton, A. (2004). Strategies for Ensuring Trustworthiness in Qualitative Research Projects. Education for Information, 22, 63-75.

Smedlund, A. (2008). The knowledge system of a firm: social capital for explicit, tacit and potential knowledge. Journal of Knowledge Management, 12, 63-77. doi:10.1108/13673270810852395

Smith, K., Collins, C., \& Clark, K. (2005). Existing Knowledge, knowledge creation capability, and the rate of new product introduction in high-technology firms. Academy of Management Journal, 48, 346-357. 
Spender, J.C. (1996). Making knowledge the basis of dynamic theory of the firm Strategic Management Journal, 17, 45-62.

Spira, J.B. (2005). In praise of knowledge workers. KM World, 14, 25-27.

Stenmark, D. (2001). Leveraging Tacit Organizational Knowledge. Journal of Management Information Systems, 17, 9-24.

Sveiby, K., \& Simons, R. (2002). Collaborative climate and effectiveness of knowledge work - an empirical study. Journal of Knowledge Management, 6, 420-433.

Teerajetgul, W., \& Chareonngam, C. (2008). Tacit knowledge utilization in Tha construction projects. Journal of Knowledge Management, 12, 64-174. doi:10.1108/13673270810852467

Thomas, G., \& Hult, M. (2003). An Integration of Thoughts on Knowledge Management. Decision Sciences, 34, 189-195. doi:10.1111/1540-5915.02264

Twinn, S. (1998). An analysis of the effectiveness of focus groups as a method of qualitative data collection with Chinese populations in nursing research. Journa of Advanced Nursing, 28, 121-132. doi:10.1046/j.1365-2648.1998.00708.x, PMid:9756235

Vishnevsky, T., \& Beanlands, H. (2004). Interpreting Research in Nephrology Nursing. Nephrology Nursing Journal, 31, 234-238. PMid:15114810

Walker, E., \& Dewar, B. (2000). Moving On From Interpretivism : An Argument For Constructivist Evaluation. Journal of Advanced Nursing, 32, 1-12. doi:10.1046/ j.1365-2648.2000.01532.x, PMid:11012816

Wang, C., \& Ahmed, P. (2003). Organisational Learning: a Critical Review. The Learning Organisation, 10, 8-17. doi:10.1108/09696470310457469
Wang-Cowham, C. (2008). HR structure and HR knowledge transfer between subsidiaries in China. The Learning Organization, 15, 26-44. doi:10.1108/09696470810842501

Watson, S., \& Hewett, K. (2006). A Multi-Theoretical Model of Knowledge Transfer in Organizations: Determinants of Knowledge Contribution and Knowledge in Organizations: Determinants of Knowledge Contribution and Knowledge Reuse. Journal of
$6486.2006 .00586 . x$

Williams, A.M. (2006). Lost in translation? International migration, learning and knowledge. Progress in Human Geography, 30, 588-607.

Woodring, J., Foley, S., Rado, G., Brown, K., \& Hamner, D. (2006). Focus Groups and Methodological Reflections. Journal of Disability Policy Studies, 16, 248-258. doi $10.1177 / 10442073060160040601$

Yakhlef, A. (2005). Immobility of tacit knowledge and the displacement of the locus of innovation. European Journal of Innovation Management, 8, 227-239. doi:10.1108/14601060510594684

Yin, R.K. (2003). Case Study Research: Design and Methods.(3rd Edn.). Thousand Oaks: Sage Publications.

Zairi, M. (1997). Business process management: a boundaryless approach to modern competitiveness Business Process Management, 3, 64-80. doi:10.1108/14637159710161585

Zemke, R. (2004). The Gray Zone. Training, 41, 1-2. 